\title{
ANALISIS KEIGO YANG DIGUNAKAN KARAKTER SAKAMOTO DALAM ANIME SAKAMOTO DESU GA
}

\section{Tiffani $^{1}$, Damai Yani ${ }^{2}$}

Program Studi Pendidikan Bahasa Jepang ${ }^{1}$ (Jurusan Bahasa dan Sastra Inggris, Fakultas

Bahasa dan Seni, Universitas Negeri Padang)

Program Studi Pendidikan Bahasa Jepang ${ }^{2}$ (Jurusan Bahasa dan Sastra Inggris, Fakultas

Bahasa dan Seni, Universitas Negeri Padang)

Email Penulis : tiffanifani4@gmail.com

\section{Sejarah Artikel \\ Submit :2019-11-12 \\ Diterima : 2019-11-14 \\ Diterbitkan : 2020-07-20}

\section{Kata Kunci:}

Keigo, sonkeigo, kenjougo, teineigo, factors that influence keigo.

\begin{abstract}
Abstrak
This study was aimed at describing the types of keigo and the factors that affect the use of keigo by Sakamoto character Sakamoto desu ga in the anime. This study was a qualitative research with a descriptive method. The data used in this study were sentences that contain keigo by Sakamoto in the anime. Moreover, the source of the data in this study was animes contained in the anime Sakamoto desu ga in the anime from episode 1-6. The results of this study were as follows: first, there were 3 types of keigo found in the anime: sonkeigo, kenjougo and teineigo. Based on the three types of keigo, there were 20 word of sonkeigo type, 9 words of kenjougo type, and 94 words of teineigo type. Then, the factors that influenced the use of keigo on anime were intimacy, age, gender, social relations, group membership, and situation.
\end{abstract}

\section{PENDAHULUAN}

Bahasa merupakan salah satu sarana komunikasi untuk menyampaikan ide, gagasan, pikiran dan perasaan seseorang. Ilmu yang mempelajari bahasa yang berkaitan dengan penggunaan bahasa di dalam masyarakat disebut sosiolinguistik (dalam Elsa, 2017 : 1).

Sosiolinguistik adalah sublinguistik yang mempelajari bahasa dalam hubungan pemakaiannya pada masyarakat. Dalam sosiolinguitik ini, antara lain, dibicarakan pemakai dan pemakaian bahasa, tempat pemakaian bahasa, tata tingkat bahasa, berbagai akibat adanya kontak dua buah bahasa atau lebih, dan ragam serta waktu pemakaian ragam bahasa itu (Nababan 1993 : 9).

Di Indonesia ada tiga bahasa yang diajarkan di instansi pendidiakan, yaitu: bahasa daerah, bahasa Indonesia, dan bahasa asing. Bahasa Indonesia merupakan bahasa nasional yang dipergunakan sebagai bahasa pengantar di sekolah, instansi pemerintahan dan lain-lain. Sedangkan bahasa asing dipergunakan untuk mengajar

${ }^{1}$ Mahasiswa Prodi Pendidikan Bahasa Jepang FBS UNP lulus pada Desember 2019

2 Dosen Prodi Pendidikan Bahasa Jepang FBS UNP 
bahasa asing dan bisa berkomunikasi dengan orang asing. Salah satu bahasa asing yang diajarkan di sekolah yang ada di Indonesia adalah bahasaJepang.

Bahasa Jepang merupakan bahasa yang unik, tidak hanya huruf yang dipakainya, tetapi juga pada strata (tingkatan) yang terdapat dalam masyarakat Jepang itu sendiri yang sangat berpengaruh terhadap kegiatan berkomunikasi, itulah yang membedakan bahasa Jepang dengan bahasa yang lainnya. Ragam bahasa hormat atau tingkat tutur dalam bahasa Jepang disebut dengan keigo.

Umumnya keigo terbagi menjadi tiga kelompok. Masaki dan Seiji (dalam Sudjianto dan Dahidi 2009: 190) membagi keigo menjadi sonkeigo, kenjougo dan teineigo. Penggunaan keigo ini tidak lepas dari faktor yang mempengaruhi keigo tersebut ketika dipakai berbicara. Adapun faktor-faktor yang mempengaruhi tingkat penggunaan keigo menurut Mizutani dalam bukunya yang berjudul How To Be In Japan (dalam Rini, 2017: 13) yaitu, keakraban, usia, hubungan sosial, status sosial, jenis kelamin, keanggotaan kelompok, dan situasi.

Selain didalam film, keigo juga sering ditemui di anime. Misalnya pada anime kuro shitsuji yang mana karakternya banyak menggunakan keigo sebagai bahasa yang sopan untuk diucapkan dengan lawan bicara. keigo merupakan tata bahasa kesopanan yang dimiliki oleh Jepang yang penggunaannya dirasa sulit untuk dipelajari. Peneliti juga memiliki ketertarikan dan ingin tahu lebih mendalam menganai keigo karena di rasa perlu untuk mempelajari keigo.

Dalam skripsi ini, peneliti ingin menganalisis jenis keigo dan faktor munculnya keigo pada karakter sakamoto dalam anime sakamoto desu ga. Anime ini adalah versi series yang produksinya diratakan agar episodenya menjadi banyak ketimbang difokuskan dalam satu film atau serial pendek yang berdurasi rata-rata 24 menit 30 detik.

Anime ini bercerita kehidupan sehari-hari siswa yang bernama sakamoto. Sakamoto adalah orang yang paling banyak menggunakan keigo. Berbeda dengan teman-teman, guru, dan warga sekolah lainnya yang menggunakan bahasa seharihari atau non formal. Selain itu, peneliti juga ingin mengetahui lebih dalam jenisjenis keigo dan faktor munculnya keigo. Oleh karena itu, peneliti bermaksud menganalisis keigo yang terdapat dalam anime sakamoto desu ga dengan judul "Analisis Keigo Pada Karakter Sakmoto Dalam Anime Sakamoto Desu Ga".

Jenis penelitian ini adalah penelitian kualitatif. Menurut Bondan dan Tylor (dalam Meleong, 2002: 3) penelitian kualitatif adalah prosedur penelitian yang menghasilkan data deskriptif berupa kata-kata tertulis atau lisan dari orang-orang dan perilaku yang dapat diamati. Penelitian ini dikatakan kualitatif karena menggunakan data deskriptif berupa data yang diukur berupa kata-kata baik tulisan maupun lisan bukan berupa data yang berupa angka. Data dari penelitian ini adalah kalimat yang menggunakan keigo yang digunakan oleh karakter Sakamoto pada anime dalam anime Sakamoto desu ga. Sedangkan sumber data yang diambil adalah 
anime dalam anime Sakamoto desu ga.

\section{METODE PENELITIAN}

Instrumen dalam penelitian ini adalah peneliti itu sendiri. Instrumen penelitian adalah suatu alat yang digunakan untuk mengukur fenomena alam maupun sosial yang diamati (Sugiyono, 2017: 305).

Adapun teknik pengumpulan data sebagai berikut. Pertama, mengumpulkan kalimat yang menggunakan keigo dengan cara mengamati, membaca dan memahami kalimat yang termasuk kedalam keigo. Kedua, mencatatnya kedalam tabel inventaris data. Kemudian dilanjutkan dengan menganalisis data dengan langkah sebagai berikut. Pertama, menglasifikasikan keigo kedalam jenisnya (sonkeigo, kenjougo, teineigo). Kedua, memasukannya data kedalam bentuk tabel data. Ketiga, mengidentifikasi data berdasarkan faktor yang mempengaruhi penggunaan keigo. Keempat, memasukanya kedalam bentuk tabel data. Kelima, melakukan analisis data dengan mendeskripsikan secara rinci.

\section{HASIL DAN PEMBAHASAN}

\section{Hasil}

Berdasarkan data pada keigo dalam anime Sakamoto Desu Ga, peneliti menemukan beberapa jenis keigo dan faktor pembentukannya. Untuk lebih jelasnya, data penelitian akan mendeskripsikan dengan tabel di bawah ini:

Table 1. Jumlah Keigo Berdasarkan Jenis

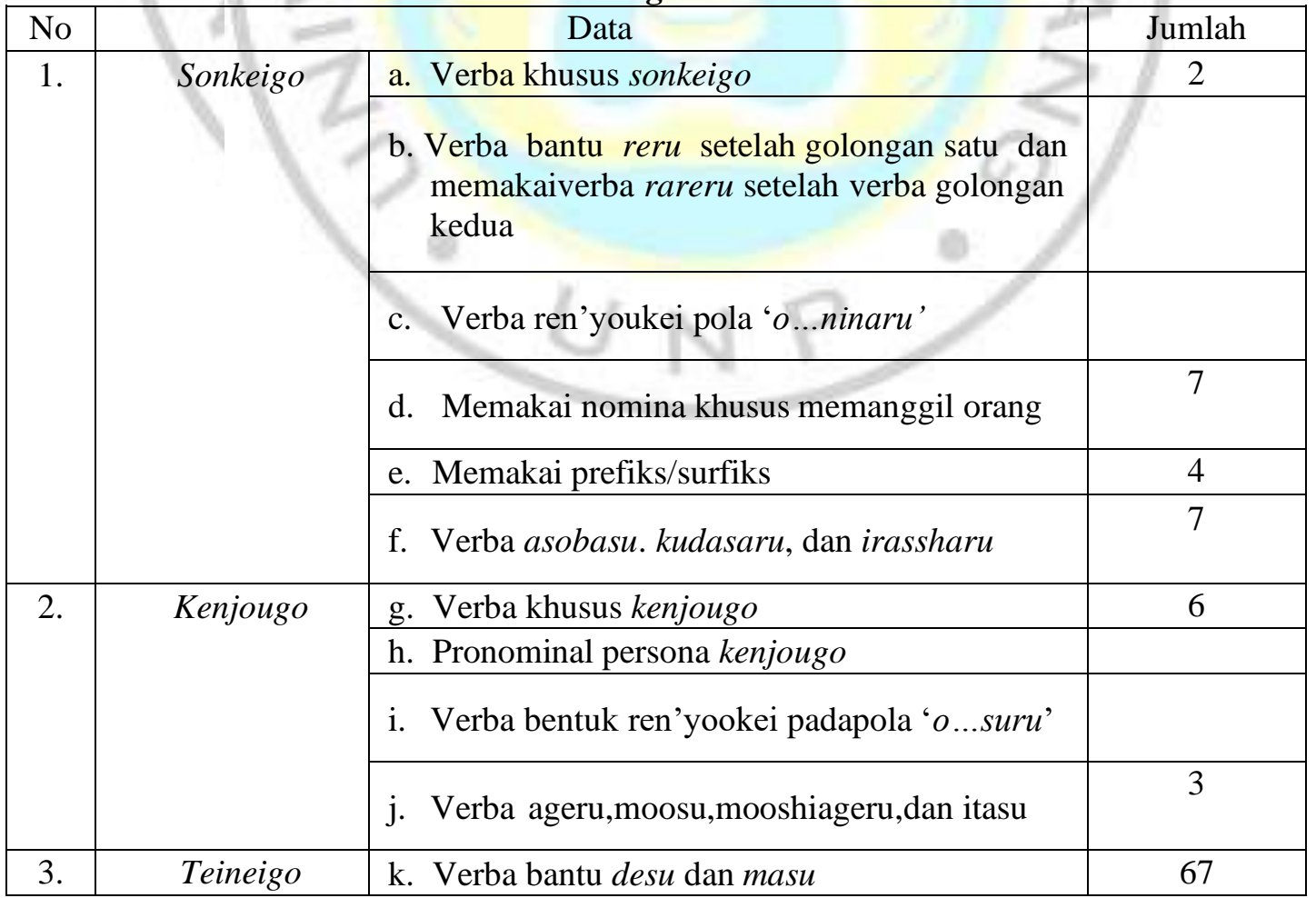




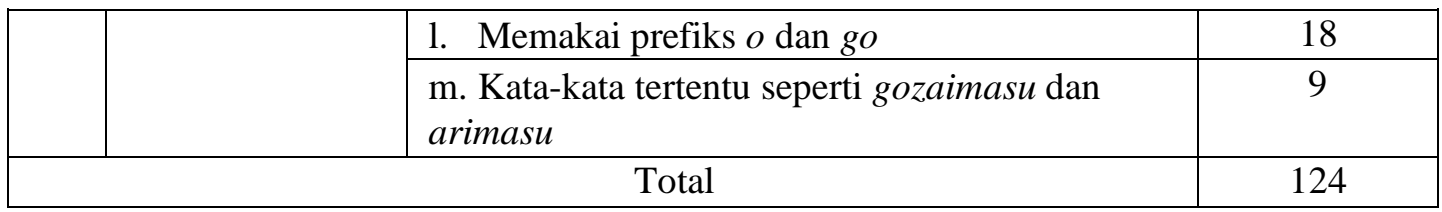

Berdasarkan tabel di atas dapat diuraikan bahwa, pada penelitian ini ditemukan 124 kata keigo. Untuk jenis sonkeigo terdapat sebanyak 20 kata dinyatakan dengan verba bentuk khusus sonkeigo 2 kata, memakai nomina pada khusus memanggil orang 7 kata, memakai prefiks/sufiks 4 kata, dan verba asobasu, kudasaru, dan irassharu 7 kata. Untuk jenis kenjougo sabanyak 6 kata dinyatakan dengan cara hanya memakai verba khusus kenjougo, memakai verba ageru, mousu, moushiageru, itasu, setelah verba lain sebanyak 3 kata. Terakhir untuk jenis teineigo terdapat sabanyak 94 kata, jenis teineigo yang paling banyak dinyatakan dalam anime Sakamoto Desu Ga ini, yaitu verba bantu desu dan masu sebanyak 67 kata, mekakai prefiks $o$ dan go sebanyak 18 kata, dan kata-kata tertentu seperti kata gozaimasu sebanyak 9 kata. Dari uraian tersebut dapat disimpulkan bahwa jenis keigo yang terdapat pada anime Sakamoto Desu Ga tersebut terdapat 3 jenis keigo. Dari 3 jenis tersebut yang paling banyak digunakan yaitu teineigo sebagai memperhalus kata saat berbicara dengan lawan bicara.

Adapun faktor yang mempengaruhi penggunaan keigo, yaitu keakraban, usia, hubungan sosial, status sosial, jenis kelamin,keanggotaan kelompok dan situasi. Dalam penelitian ini hanya beberapa faktor yang mempengaruhi keigo pada anime ini. Untuk lebih jelasnya, akan dideskripsikan pada tabel dibawah ini.

Table 2. Faktor Yang Mempengaruhi Keigo

\begin{tabular}{|c|l|c|}
\hline No & \multicolumn{1}{|c|}{ Faktor Yang Mempengaruhi Keigo } & Jumlah \\
\hline 1 & Keakraban & 5 \\
\hline 2 & Usia & 17 \\
\hline 3 & Hubungan sosial & 13 \\
\hline 4 & Status sosial & 3 \\
\hline 5 & Jenis kelamin & 1 \\
\hline 6 & Keanggotaan kelompok & 42 \\
\hline 7 & Situasi Total & 81 \\
\hline
\end{tabular}

Berdasarkan tabel di atas dapat diketahui bahwa, pada penelitian ini ditemukan 6 faktor yang mempengaruhi penggunaan keigo pada anime Sakamoto Desu Ga dengan 81 data Keigo berdasarkan faktor yang mempengaruhinya. Faktor yang mempengaruhinya terdiri dari keakraban sebanyak 5 data, usia sebanyak 17 data, hubungan sosial sebanyak 13 data, jenis kelamin sebanyak 3 data, keanggotaan kelompok sebanyak 1 data dan yang terakhir situasi sebanyak 42 data. Dari 6 jenis faktor yang memunculkan keigo yang paling banyak adalah situasi dengan 42 data. 


\section{Pembahasan}

Berdasarkan analisis data di atas, peneliti menemukan 3 jenis keigo yang terdapat pada anime Sakamoto Desu Ga. Sebagaimana menurut Sudjianto dan Dahidi (2009: 190-195) keigo terbagi atas 3 yaitu sonkeigo, kenjougo dan teineigo. Untuk jenis sonkeigo ditemukan sebanyak 20 kata, dari 20 kata tersebut sonkeigo dapat dinyatakan dengan cara pertama, memakai verba khusus sonkeigo sebanyak 2 kata seperti kata[ お召し上がり]. kedua, memakai nomina khusus memanggil orang sebanyak 7 seperti kata [ティーチャー]. Ketiga, memakai prefiks/sufiks sebanyak 4 kata seperti [お客様]. Keempat, memakai verba asobasu, kudasaru, dan irassharu sabanyak 7 kata seperti [てください].

Jenis kenjougo terdapar sebanyak 9 kata, dari 9 kata kenjougo tersebut dinyatakan memakai verba khusus kenjougo sebanyak 6 kataseperti [いただきまし た]. Terakhir, jenis teineigo ditemukan sebanyak 94 kata, dari 94 kata tersebut dinyatakan dengan cara pertama, memakai verba bentuk desu dan masu sebanyak 67 kata. Dari 67 kata tersebut 30 kata tersebut menggunakan bentuk desu, seperti kata [ 責任です]. Dan 37 kata menggunakan kata verb bentuk masu, seperti kata [あり ます]. Kedua, memakai prefiks $o$ dan go sebanyak 18 kata, dari 18 kata tersebut

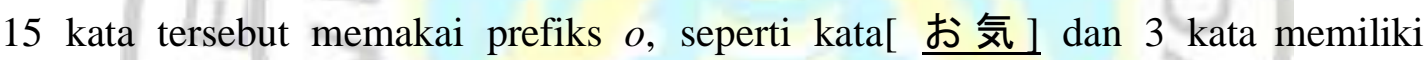
prefiks go, seperti [ご用意いた]. ketiga, memakai kata-kata tertentu seperti gozaimasu sebanyak 9 kata, dari 9 kata terdapat bentuk gozaimasu sebanyak 6 kata seperti kata [ございました]. Dan 3 kata bentuk arimasu sepertikata [はありませ L].

Selanjutnya, faktor yang mempengaruhi penggunaan keigo yang terdapat dalam anime Sakamoto Desu Ga yaitu terdapat faktor keakraban, faktor usia, faktor hubungan sosial, dan faktor jenis kelamin, keanggotaan kelompok dan situasi. Sebagaimana yang dikemukakan oleh Mizutani (dalam Rini, 2017: 13) menguraikan faktor yang mempengaruhi penggunaan keigo sebagai berikut. (1) keakraban, (2) usia, (3) hubungan sosial, (4) status sosial, (5) jenis kelamin, (6) keanggotaan kelompok, dan (7) situasi. Dari 7 faktor tersebut, hanya menemukan 6 faktor saja. Dalam anime Sakamoto Desu $G a$ terdapat faktor keakraban, faktor usia, faktor hubungan sosial, faktor jenis kelamin, faktor keanggotaan kelompok dan faktor situasi.

Dalam penelitian jenis keigo dan faktor yang memperngarui dalam anime Sakamoto Desu Ga, untuk jenis keigo paling banyak ditemukan yaitu teineigo sebanyak 124 kata. Jenis teineigo ini merupakan bentuk memperhalus kata yang dipakai untuk menghormati lawan bicara atau orang yang dibicarakan. Dari data.sudah ditemukan, teineigo yang dinyatakan dengan memakai verba bantu desu dan masu sebanyak 67 kata, memakai prefiks $o$ dan go sebanyak 18 kata, memakai kata-kata tertentu seperti gozaimasu sebanyak 9 kata. Selain itu faktor yang 
mempengaruhi keigo dalam anime Sakamoto Desu Ga tersebut yaitu faktor keakraaban, usia, hubungan sosial, jenis kelamin, keanggotaan kelompok, dan situasi.

Kemudian jika dibandingkan dengan penelitian relevan yang dilakukan oleh Elsa (2017) dalam penelitiannya lebih banyak mendapatkan bentuk merendahkan diri yaitu kenjougo ketika berinteraksi dengan orang lain [そとのひと ], sedangkan teineigo terdapat hanya sedikit. Hal ini untuk mensejajarkan tingkat kesopanan dalam berbicara. Dan penggunaan sonkeigo untuk meninggikanlawan bicara.

Selain dengan penelitian Elsa (2017), dalam penelitian ini ditemukan lebih banyak kenjougo sebanyak 9 kata, penggunaan kenjougo ini dikarenakan faktor yang mempengaruhi penggunaan keigo tersebut yaitu faktor keakraban, usia dan hubungan sosial. Hal ini dapat dikatakan bahwa ketika berbicara terhadap orang luar (soto no hito) seseorang akan menggunakan bentuk merendahkan diri sebagai bentuk sopan untuk menunjukkan rasa hormatnya kepada lawan bicara. Tidak hanya kenjougo, sonkeigo juga digunakan ketika berbicara dengan orang luar (soto no hito) dan kepada orang yang belum akrab sebagai bentuk penghormatan. Dan penggunaan teineigo sebagai bentuk memperhalus ucapan ketika menggunakan berbicara dengan lawan bicara.

\section{KESIMPULAN}

Berdasarkan hasil penelitian jenis dan faktor yang mempengaruhi penggunaan keigo dan faktor yang mempengaruhi penggunaan keigo pada anime Sakamoto Desu Ga, dapat disimpulkan bahwa pada jenis keigo anime terdapat lebih banyak penggunaan teineigo (memperhalus kata). Adapun data teineigo yang ditemukan sebanyak 97 kata. Dari 97 jenis teineigo tersebut, yang dinyatakan dengan memakai verba bantu desu dan masu sebanyak 67 kata, memaki prefiks $o$ dan go sebanyak $18 \mathrm{kata}$, dan memkai kata-kata tertentu seperti gozaimasu sebanyak 9 kata. Untuk sonkeigo (bentuk meninggikan) ketika berbicara dengan orang yang belum akrab atau kepada orang luar (soto no hito), terdapat 22 kata, yang dinyatakan memakai verba khusus sebanyak 3 kata, memakai nomina khusus memanggil orang sabanyak 7 kata, menggunakan prefiks / sufiks sebagai sonkeigo sebanyak 4 kata, memakai 'asobasu', 'kudasaru', dan 'irassharu' sebanyak 7 kata. Terakhir jenis kenjougo (bentuk merendahkan diri) ketika berbicara dengan orang yang belum akrab, dan kepada orang luar (soto no hito) sebanyak 9 kata. Memakai verba khusus kenjougo sebanyak 6 kata, memakai verba ageru,mousu,moushiageru, dan itasu sebanyak 3 kata.

Faktor yang mempengaruhi keigo pada anime Sakamoto Desu Ga terdapat 6 faktor dengan jumlah 87 data. yaitu faktor keakraban sebanyak 5 data, faktor usia sebanyak 17 data, faktor hubungan sosial sebanyak 13 data, faktor jenis kelamin sebanyak 5 data, faktor keanggotaan kelompok sebanyak 5 data, dan faktor situasi sebanyak 87 data.

Berbicara dalam bahasa Jepang sangat memperhatikan bentuk ungkapan yang menunjukkan kesopanan dan bentuk penghormatan yang tinggi kepada lawan 
bicara. Bentuk sopan atau hormat dinyatakan dengan adanya bentuk keigo yang dibagi menjadi tiga jenis, yaitu sonkeigo, kenjougo dan teineigo. Pengguanaan ragam bentuk keigo pada anime dapat dilihat dari faktor yang mempengaruhi penggunaan keigo itu sendiri. Seperti situasi, keakraban, hubunagan sosial, keanggotaan kelompok, jenis kelamin, usia, dan status sosial yang mempengaruhi keigo tersebut.

Hal ini bertujuan untuk mengetahui jenis bahasa keigo yang mana harus dipakai ketika berbicara. Pemilihan bentuk keigo ini diharapkan dapat menghindari kesalahan dalam berinteraksi yang akan merubah makna atau terkesan kurang sopan. Penggunaan bahasa hormat termasuk ketentuan berbicara yang memiliki bahasa baku dan juga pemakaian bahasa kesopanannya.

\section{REFERENSI}

Angga Rini, Elsa. 2017. "Analisis Bahasa Hormat (Keigo) dalam Film Nazotoki Wa Dinner No Atode". Laporan Penelitian. Semarang:FIB UNDIP, (Online), (http://eprint.ac.id/51751/1/Skripsi .pdf, diakses 6 Mei 2018).

Anoboy.Anime Sakamoto Desu Ga. (diakses pada 20 desember 2018). http://anoboy.com

Chaer, Abdul. 2012. Linguistik Umum. Jakarta: Rineka Cipta.

Chaer, Abdul dan Leonis Agustina. 2010. Sosiolinguistik Perkenalan Awal.Jakarta: Rineka Cipta.

Djajasudarman.2010. Metode Linguistik: Ancangan Metode Penelitia dan Kajian.Bandung: Reflika Aditama

Ermanto dan Emidar. 2016. Bahasa Indonesia. Padang: UNP Press.

Kimura, Muneo. 1988. Dasar-Dasar Metodologi Prngajaran Bahasa Jepang.Edisi Indonesia. Tokyo: Bonjinsha

Mahsun. 2007. Metodologi Penelitian Bahasa: Tahap Strategi, Metode dan Tekniknya. Jakarta: PT. Raja Grafindo Persada.

Meleong, Lexy J. 2011. Metode Penelitian Kualitatif. Bandung: PT. Remaja Rosdakarya.

Mizutani, Osamu dan Nobuko Mizutani.1987. How tobe Polite in Japanese.Tokyo: The Japan Times.

Nasihin, Anwar. 2002. Dasar-dasar Korespondensi Jepang. Padang: Universitas Bung Hatta. 
Nababan.1993. Sosiolinguistik Suatu Pengantar. Jakarta : Gramedia Pustaka Utama.

Sanada,Shinji, et al.1995. Shakaigengogaku. Tokyo:Oufuu.

Purwanti, Rina. 2011. "Pengaruh Peggunaan Teknik Stars Terhadap Kemamapuan Membaca Huruf Hiragana dan Katakana. Skripsi. Bandung:FBS UPI.

Prayuda Sumirat, Angga. 2015. "Analisis Deskritif Songkeigo dan Kenjougo dalam Anime Kuro Shitsuji". Laporan Penelitian . Bandung:FBS UPI

Sudjianto dan Ahmad Dahidi. 2009. Pengantar Linguistik Bahasa Jepang. Jakarta:Kesaint Blanc.

Sudaryanto. 1993. Metode dan Aneka Teknik Analisis Bahasa Pengantar Wacana Wahana Kebudayaan Secara Linguistik. Yogyakarta: Duta Wacana University Press.

Sugiyono. 2017. Metode Penelitian Kuantitatif dan Kualitatif. Bandung: Alfabeta. Sumarsono. 2009. Sosiolinguistik. Yogyakarta: Pustaka Pelajar.

Sutedi,Dedi. 2014. Dasar-Dasar Linguistik Bahasa Jepang. Bandung: Humaniora Utama Press.

Somantri, Andika. 2016. "Analisis Penggunaan Keigo Dalam Lingkungan Kerja Pada Film Kenchou Omotenashika”. Bandung:FBS UPI.

Wulansuci, Yolanda. 2010. "Budaya Populer Manga dan Anime Sebagai Soft Power Jepang”. Skripsi.

Yani, Damai. 2016. "Metode Audio-Lingual Dalam Pembelajaran Kaiwa". Jurnal.Padang:UNP http://ejournal.unp.ac.id/index.php/linguadidaktika/article/view/6325) (diakses 4 oktober 2019)

Zaim, M. 2014. Metode Penelitian Bahasa. Padang: FBS UNP Press. 